doi: $10.2306 /$ scienceasia1513-1874.2013.39.036

\title{
Tetrahymena-specific biomass evaluation with a DNA-based method
}

\author{
Qingyun Yan ${ }^{\mathrm{a}}$, Yuhe Yu${ }^{\mathrm{a}, *}$, Lili Dai ${ }^{\mathrm{a}, \mathrm{b}}$ \\ a Key Laboratory of Aquatic Biodiversity and Conservation of Chinese Academy of Sciences, \\ Institute of Hydrobiology, Chinese Academy of Sciences, Wuhan 430072 China \\ b Graduate University of Chinese Academy of Sciences, Beijing 100049 China \\ *Corresponding author, e-mail: yhyu@ihb.ac.cn
}

Received 16 May 2012

Accepted 28 Nov 2012

\begin{abstract}
Evaluating the biomass of a specific taxon or that of a certain nutritional level is especially important for understanding an ecosystem. Although various methods are available, there is still a lack of a universally accepted approach for taxa-specific biomass evaluation. Taking cultured unicellular Tetrahymena as an example, the present study is aimed at exploring and highlighting a DNA-based method for taxa-specific biomass estimation. Results indicated that the Tetrahymena DNA yield increased linearly with increasing number of Tetrahymena cells $(p<0.001)$. The intra and inter real-time quantitative PCR (Q-PCR) assays were highly reproducible, and Q-PCR quantifying 18S rDNA could detect an equivalent quantity of a single cell or less. Tetrahymena-specific biomass then can be determined according to the rDNA copies quantified by Q-PCR $(p<0.002)$, considering both of species richness and evenness (indicated by the pooled cells of Tetrahymena species with different ratios). Observations of the present study together with some others suggest that it is possible to quantify a target micro-biomass in natural ambience via specifically-amplified genes.
\end{abstract}

KEYWORDS: genomic DNA, real-time quantitative PCR, molecular methods

\section{INTRODUCTION}

Increasing evidence suggest that biomass evaluation has historically been an important ecological issue, which provides fundamental knowledge to reveal structural and functional roles of target organisms in an ecosystem ${ }^{1,2}$. It also gives us valuable information to facilitate ecosystem management and enable prediction of some potential ecological risk. Therefore, biomass evaluation has historically been one of focuses in ecological studies. During the past decades, various methods (direct or indirect) have been developed to evaluate the biomass of different organisms ${ }^{2}$, and constant efforts have also been made to improve the efficiency and veracity of biomass determination. However, there still lack of an approach to determine taxa-specific biomass, especially for microeukaryotes.

Classical direct biomass evaluation methods (e.g., viable count, epifluorescence filter technique, coulter counter, and electron microscopy) mainly based on measuring cell mass/number ${ }^{1}$, and traditional indirect quantification usually on the basis of specific components (e.g., protein, carbon/phosphate, ATP) ${ }^{3}$ or some metabolic activities (e.g., $\mathrm{O}_{2}$ uptake, $\mathrm{CO}_{2}$ production $)^{4}$. These methods are generally time- consuming and often accompany with large errors ${ }^{5}$. Furthermore, evaluation may become more complicated and inaccurate when insoluble substrates are employed ${ }^{1}$. Although on-line monitoring techniques (e.g., microcalorimetry, fluorescence, spectroscopy, electrical properties) are recently been developed, there still lack of ideal monitor sensor ${ }^{2}$. On the other hand, these methods can only evaluate the total quantity of all organisms in a particular sample, but the biomass of genus/groups interested is very difficult to quantify. Therefore, in order to reveal biomass and facilitate comparisons within or between certain nutritional levels, there is an urgent need for strategy of taxa-specific biomass evaluation, which will undoubtedly do great contribution to ecological study.

Deoxyribonucleic acid (DNA) is universally present in different kinds of organisms, regardless of the life forms or stages, and its content highly correlated with growth rate and some other crucial life activities $^{6}$. DNA content may be one of good parameters that can be linked to biomass ${ }^{6,7}$. With rapid development of molecular techniques and dramatically increased collection of nucleotide sequences, it is easy to design primers targeting different taxonomic levels to amplify particular genes. Some genes present 
stable copies per cell (e.g., rRNA gene in unicellular Tetrahymena $)^{8}$, and some genes even can be used as DNA barcoding for taxonomic classification (e.g., cytochrome c oxidase I gene for animals) ${ }^{9}$. Therefore, taxa-specific biomass perhaps can be realized with a bridge of specifically amplified gene. Recently developed real-time quantitative PCR (Q-PCR) just provide a simple and elegant method for determining the amount of target genes ${ }^{10-14}$. The example of Tetrahymena analysis in the present study was applied to validate the feasibility of applying DNAbased methods (e.g., Q-PCR) to determine Tetrahymena-specific biomass. It also highlighted promising perspectives of taxa-specific biomass evaluation with DNA-based methods in ecological study.

\section{MATERIALS AND METHODS}

\section{Tetrahymena Culture and DNA extraction}

Five Tetrahymena species (T. pigmentosa, T. pyriformis, T. thermophila, T. borealis, and T. corlissi) were cultured axenically at $27{ }^{\circ} \mathrm{C}$ in a medium containing $2.0 \%$ proteose peptone (Oxoid, USA), $0.1 \%$ yeast extract (Oxoid, USA), $0.2 \%$ glucose and $0.03 \%$ sequestrene (Fe-EDTA). Fifty millilitres of cultured cells (at the exponential phase) were harvested by centrifuging at $3000 \mathrm{~g}$ for $3 \mathrm{~min}$, then resuspended and incubated in $1.0 \mathrm{ml}$ fresh culture medium, and $100 \mu \mathrm{l}$ was used to determine the cell density using a Beckman Coulter (Beckman, USA). Then, different resuspended cells (less than $4 \times 10^{5}$ cells were used as the manufacturer suggested to improve the separation efficiency) were applied for DNA extraction using a genomic DNA extraction kit according to the manufacturer's instructions (Fermentas, USA). Initially, $0.1 \mathrm{mg} / \mathrm{ml}$ of proteinase $\mathrm{K}$ (final concentration) was added in the lysis solution before $65^{\circ} \mathrm{C}$ incubation. Additionally, $0.2 \mathrm{mg} / \mathrm{ml}$ of ribonuclease A (final concentration) was added and incubated for $10 \mathrm{~min}$ at $37^{\circ} \mathrm{C}$ prior to DNA precipitate. The extracted DNA was dissolved in $50 \mu \mathrm{l}$ sterile water and stored at $-20^{\circ} \mathrm{C}$ until used. The DNA yield and quality were assessed based on the absorbance determined by biophotometer spectrophotometer (Eppendorf, Germany). DNA extraction efficiency was then evaluated by extracting genomic DNA from different amounts of cells with three replications.

\section{Real-time quantitative PCR standards}

For quantification of the Tetrahymena samples, Q-PCR standards with known amounts of plasmid DNA were created. In brief, PCR products of T. pigmentosa $18 \mathrm{~S}$ rDNA were gel-purified, cloned into pMD18-T vector, and then transformed into $E s$ cherichia coli cells (DH5 $\alpha$ strain). After confirmed by sequencing, plasmid DNA containing cloned $18 \mathrm{~S}$ rDNA of T. pigmentosa was extracted using TIANprep mini plasmid kit (Tiangen, China) following manufacturer's instructions. The concentrations of plasmid DNA were determined by spectrophotometry with serial dilutions, and the corresponding copy numbers were calculated according to the method described by Smith et $\mathrm{al}^{15}$. Serial tenfold dilution from $3.08 \times 10^{3}$ to $3.08 \times 10^{7}$ (copies/ $\mu$ l) were used in Q-PCR for establishing standard curves, assuming that the amplification efficiency of plasmid DNA was equal to the amplification efficiency of target 18S rDNA from different Tetrahymena species. There were three notemplate negative controls (NTC) on each plate to screen possible contamination, check primer-dimer formation, and to set background fluorescence for plate normalization. The slope, $y$-intercept, $R^{2}$ and amplification efficiency of each standard curve were determined using the Sequence Detection System software (Applied Biosystems, USA) with a fixed threshold according to Adams ${ }^{16}$.

\section{Sample quantification and biomass evaluation}

The 18S rRNA gene was amplified according to $\mathrm{Fu}$ and Miao ${ }^{17}$ for determining rDNA concentration of each unknown sample. Q-PCR quantification of $18 \mathrm{~S}$ rDNA present in each sample was performed using an ABI prism 7300 real-time PCR System (Applied biosystems, USA). Each PCR amplification reaction (20 $\mu \mathrm{l})$ containing $10 \mu \mathrm{l} \mathrm{SYBR}$ Green real-time PCR master mix QPK-201 (Toyobo, Japan), $0.05 \mu \mathrm{M}$ of each primer (18S-F: 5'-CCTGGGAAGGTACG GGTAAT-3', 18S-R: 5'-AAGGTTCACCAGA CCATTCG- $\left.3^{\prime}\right)^{17}$ and about 5 ng DNA template. PCR cycling include an initial denaturation for $4 \mathrm{~min}$ at $94^{\circ} \mathrm{C}$, followed by 40 cycles of $94^{\circ} \mathrm{C}$ for $20 \mathrm{~s}$, $65^{\circ} \mathrm{C}$ for $20 \mathrm{~s}$, then $72^{\circ} \mathrm{C}$ for $45 \mathrm{~s}$. Fluorescence readings were taken at each extension step, and a final melting analysis was performed to check for nonspecific product formation. The amplicons were also visualized using agarose gel to verify single product formation with expected molecular weight (MW). For evaluation of PCR template competition and the possible interaction among difference species (including Tetrahymena species and non-target species), DNA of single, couple and five species (regarding species richness) were mixed with different ratios (regarding species evenness) for Q-PCR analysis, and PCR were performed in separate assays with three replications for each sample. 


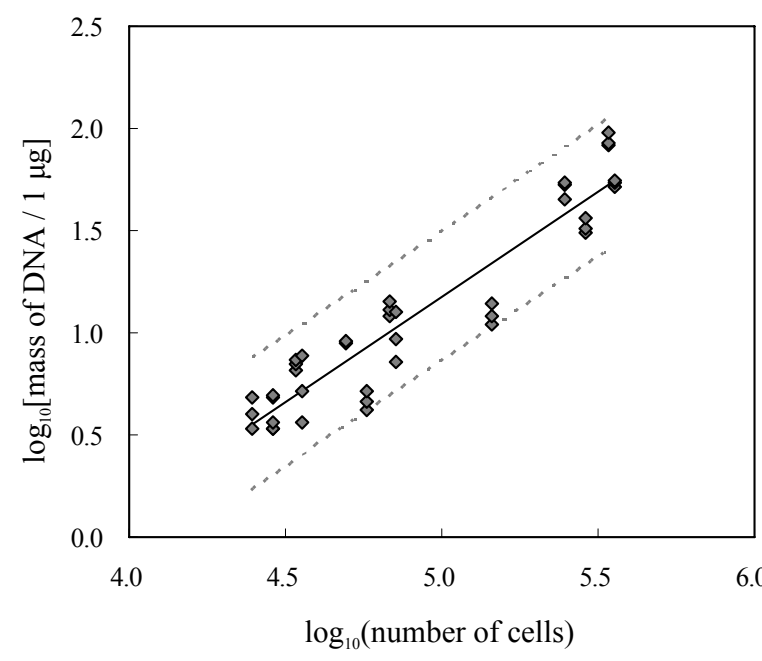

Fig. 1 Regressing cell number of Tetrahymena against the DNA yield, showing observations $(\diamond)$, predictions (solid line), and 95\% confidence on predictions (dotted lines).

\section{Statistical analysis}

Data were analysed with software of SPSS 13.0, XLSTAT-PRO 7.5 or ABI 7300 SDS. Data sets with large span between samples (e.g., numbers of $18 \mathrm{~S}$ rDNA copy, number of cells) were performed with log-transformation (base 10) before analysis. The variation among samples was investigated using one way ANOVA, and paired $t$-tests were carried out to test for any significant differences between replications and samples. Regression analysis was applied to check the correlation between cell numbers and DNA yields, further regression was performed to estimate the relations between rDNA copies and target biomass.

\section{RESULTS}

\section{DNA extraction and preliminary real-time quantitative PCR}

The extracted genomic DNAs were initially evaluated using $0.7 \%$ agarose gel electrophoresis, and each sample showed a clear genomic DNA band. DNA yields from different amounts of cells indicated that the amounts of genomic DNA increased linearly with increasing number of cells $\left(R^{2}=0.89, P<0.001\right.$, Fig. 1). The 10-1000 fold dilutions of extracted DNA tested by Q-PCR can show positive cycle threshold $(C t)$ values, but negative controls did not detect $C t$ value in 40 PCR cycles. Melting curve analysis consistently showed that amplification of all samples produced one sharp peak. The amplicons visualized in agarose gel also indicated single product with the

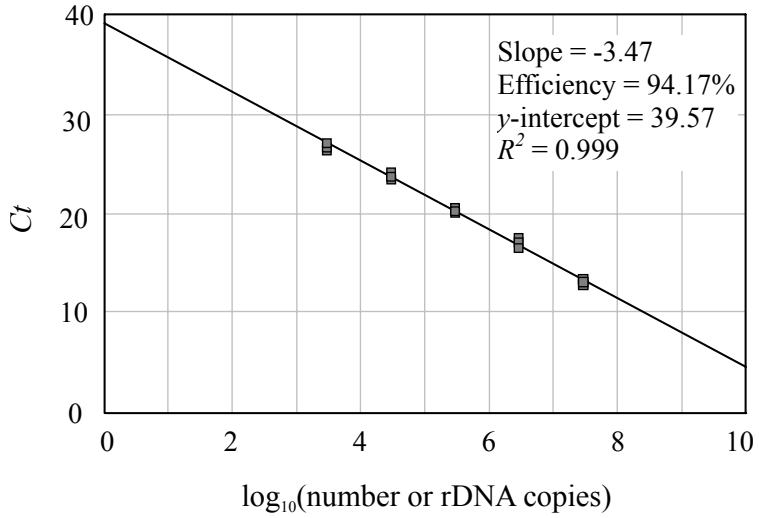

Fig. 2 Example of qualitative PCR amplification from known amounts of plasmid DNA to construct standard curves for quantification of unknown samples.

expected MW, and no primer-dimer formation was detected in NTC. All these observations suggested that the extracted DNAs met the requirement of Q-PCR analysis.

\section{Reproducibility of real-time quantitative PCR}

Q-PCR analysis on different concentration of known plasmid DNA (from $3.08 \times 10^{3}$ to $3.08 \times 10^{7}$ copies $/ \mu \mathrm{l}$ ) showed higher reproducibility of intra(replicate Q-PCR amplifications in the same experiment plate) and inter-assays (replicate Q-PCR amplifications in separate plates). The known amount of standards revealed a strong liner relationship between starting rDNA copies and $C t\left(R^{2}=0.999\right.$, Fig. 2) with amplification efficiency from $94 \%$ to $96 \%$ (Table 1). The six individual standard curves (three replications in each of the two separate assays) were highly reproducible and differences between them were not significant $(p>0.05)$. Covariance analysis also showed no significant differences in slope $(p>0.44)$, efficiency $(p>0.46)$, and $y$-intercept $(p>0.33)$ of the six standard curves. Over the linear range of these standards, the average coefficient of variation $(\mathrm{CV})$ of the $C t$ values within assays only ranged from $0.18 \%$ to $0.96 \%$, and that between assays ranged from $0.45 \%$ to $3.07 \%$. When applied these standard curves to quantify the unknown samples, results indicated that the $C t$ values of each sample (three replicates in each separate Q-PCR assay) were also not significantly different $(p>0.05)$. All these suggesting high reproducibility as well as reliability in the present Q-PCR assays, and therefore it can be applied for sample quantification. 
Table 1 Regression coefficient $\left(R^{2}\right)$, slope, amplification efficiency, and $y$-intercept values of different standard curves, amplified in separate Q-PCR assays.

\begin{tabular}{lcccccccc}
\hline & \multicolumn{3}{c}{ Q-PCR assay 1 } & & \multicolumn{3}{c}{ Q-PCR assay 2 } & $p$ value of \\
\cline { 2 - 3 } & $\mathrm{A}$ & $\mathrm{B}$ & $\mathrm{C}$ & & $\mathrm{A}$ & $\mathrm{B}$ & $\mathrm{C}$ & \\
inter-assays \\
\hline$R^{2}$ & 0.999 & 0.999 & 0.999 & & 0.999 & 0.999 & 0.999 & - \\
Slope & -3.48 & -3.46 & -3.48 & & -3.42 & -3.46 & -3.42 & 0.06 \\
Efficiency (\%) & 93.82 & 94.49 & 93.73 & & 96.25 & 94.40 & 96.11 & 0.07 \\
$y$-intercept & 39.51 & 39.50 & 39.70 & & 39.60 & 39.98 & 39.85 & 0.14 \\
\hline
\end{tabular}

A, B and C indicated the duplicate standard curves in the same Q-PCR assay plate.

\section{Sample quantification and biomass evaluation}

Duplications of non-target negative controls (containing no Tetrahymena DNA, but only bacterial DNA as template) gave fluorescence signal similar to that of NTC. However, a relatively low content of target DNA (0.14 ng applied herein) can be detected and showing positive fluorescence signal $(C t \approx 32)$. The $C t$ values for standards and unknown samples ranged from 1328 (corresponding to gene copies from $10^{3}$ to $10^{7}$ ), and all the NTC (three replications in each run) did not detect $C t$ value in the 40 cycles of PCR. The average coefficient of variation $(\mathrm{CV})$ of $C t$ value for the triplicate unknown samples within Q-PCR assays ranged from $0.10 \%$ to $0.67 \%$, that between Q-PCR assays was also very low (ranging from $0.18 \%$ to $1.64 \%$ ). By analysing logarithms transformation (base 10 ) of the $18 \mathrm{~S}$ rDNA (copies $/ \mu \mathrm{l}$ ) initially presented in the PCR mixture, its mean CV ranged from $0.11 \%$ to $0.84 \%$, and from $0.26 \%$ to $1.51 \%$ for intra- and inter-assays, respectively. Here we only performed comparison of $18 \mathrm{~S}$ rDNA copies of different samples and their triplications within Q-PCR assay as recommend by Smith et $a^{15}$. According to the value of Tetrahymena per cell ${ }^{18,19}$, linear regression equations can be established between Tetrahymena biomass and the determined rDNA copies $\left(R^{2}>0.99, p<0.002\right)$.

\section{DISCUSSION}

Biomass evaluation has historically been a crucial step encountered to study the key ecological issues such as productivity, metabolism ${ }^{1,2}$. However, evaluating microbial biomass with direct counting or indirect physical/chemical methods are generally complicated, time consuming ${ }^{1,5}$, and taxa-specific evaluation with these traditional methods is even impossible. DNA is a fundamental constituent of all organisms and showed close relation to biological productivity ${ }^{20}$, and therefore the content of DNA has also been used as an indicator of microbial biomass ${ }^{6,21}$. However, direct DNA content measurement using spectrophotometry, high performance liquid chromatography, or some other protocols still suffered from lack of precision and reliability due to number of factors ${ }^{22}$.

With increasing availability of reliable procedures to extract metagenomic DNA, and benefit from rapidly developed molecular technology such as Q-PCR. Quantification of bacterial ${ }^{23}$, fungal ${ }^{10}$, rumen protozoal $^{11}$, and algal abundance ${ }^{13,14}$ with amplicons of rRNA gene or ITS region has been validated to determine total biomass of targeted microorganisms. However, few attempts have been made to the taxa-specific (e.g., genus level) biomass evaluation. For all DNA-based molecular analysis, successful DNA recovery is the first prerequisite. Results of the present study indicate that using different number of cells applied in DNA extraction consistently produce higher yields of genomic DNA. The DNA amount was linearly related to the number of pooled Tetrahymena cells (Fig. 1), indicating that the recovery efficiency and reproducibility of DNA extraction were reliable. The dilutions of extracted DNA tested in preliminary Q-PCR also indicated that the obtained genomic DNA met the requirement of subsequent analysis.

Generally, most organisms in an ecosystem belong to a few numerically dominant species and many species with low abundance ${ }^{24}$. Therefore, multiple species with different ratios were pooled and applied herein for PCR to simulate DNAs competitions as that derived from natural environmental samples. Also, attention should be paid to PCR reproducibility, which has been satisfied in the present study (Table 1, Fig. 2) for our further biomass determination. As the 18S rRNA gene copies of Tetrahymena are relatively stable $^{8,25}$, here we applied $18 \mathrm{~S}$ rDNA as a marker to explore the Tetrahymena-specific biomass evaluation. Although relative lower of Tetrahymena DNA $(0.14 \mathrm{ng})$ could be detected in Q-PCR analysis, we did not use that lower level of DNA in order to get a relative higher $C t$ value for sample quantification. Because low copy number will be less accurate than that quantifying high gene copies due to a higher 
proportion of negative signals in the former determination ${ }^{15}$. With the optimized Q-PCR conditions, final analysis suggested that Tetrahymena-specific biomass can be realized according to the rDNA copies determined by Q-PCR. Furthermore, the interactions and effects resulted from coexistence of multi-species can be reflected by their relative abundance. Although the present study only addressed cultured Tetrahymena simulating simple environmental conditions, these results have highlighted new insights into taxaspecific biomass evaluation regarding other eukaryotic microorganisms with DNA-based methods.

Sequences available in public databases (e.g., GenBank: http://www.ncbi.nlm.nih.gov; EMBL: http: //www.ebi.ac.uk/embl; DDBJ: http://www.ddbj.nig. ac.jp) have been proliferating continuously as a result in the improvement of sequencing technology, especially after the use of clone library-based metagenome $e^{26}$ and ultra-high-throughput sequencing approaches ${ }^{27}$. Undoubtedly, more and more new/update sequences will be available, and therefore will greatly enhance our ability to design appropriate taxa-specific primers/probes to address taxa-specific biomass evaluation. On the other hand, combining different DNA-based approaches have provided promising insight into microbial ecology ${ }^{28-30}$, which will also strengthen DNA-based biomass evaluation. For example, the microarrays, which increasingly used in screening the presence of specific taxa or functional genes from environmental microbial communities ${ }^{31}$, provided opportunity to undertake the DNA-based biomass evaluation of environmental samples. With an initial amplification step before hybridization, microarrays could be used for quantitative assessments of gene abundance ${ }^{32}$. Therefore, quantitative changes in taxa-specific biomass can be validated by microarrays combining with Q-PCR based approaches. Another example is the DNA barcoding, which provided powerful tool for taxonomic and biodiversity research $^{33}$, will also contribute to the taxa-specific biomass evaluation if microorganisms of interest in the environmental samples can be identified according to a standardized DNA region.

As discussed above, it is reasonable to believe that with continuing development of currently used methods and introduction of some more refined techniques, the DNA-based taxa-specific biomass evaluation will increase our potency to understand the ecological function of different groups in the ecosystem. Of course, when applying this strategy to evaluate microbial biomass in environmental samples, it should note the varying cellular copy numbers of target gene operon ${ }^{31}$. Thus number of gene copies ought to be estimated with cells representing target species belonging to different phylogenetic groups in advance $^{13}$. Another important point is the weight per cell may not be fixed, especially for organisms under different environmental conditions. These problems need further studies to find more appropriate target genes with stable copies, and works are also needed to search for practical conversion between gene copies and biomass.

Acknowledgements: We appreciate Dr Wei Miao from Institute of Hydrobiology, Chinese Academy of Sciences providing the cultured cells of T. thermophila, T. pigmentosa, T. pyriformis, and thanks also to Dr Denis Lynn (University of Guelph, Canada) for providing T. borealis, T. corlissi. This study was funded by the National Natural Science Foundation of China (31071896), the Knowledge Innovation Program of the Chinese Academy of Sciences (Y15E04), the Key Laboratory of Marine and Estuarine Fisheries Resources and Ecology, Ministry of Agriculture (201007), and the Youth Innovation Promotion Association, CAS (Y22Z07).

\section{REFERENCES}

1. Singh A, Kuhad RC, Sahai V, Ghosh P (1994) Evaluation of biomass. Adv Biochem Eng Biotechnol 51, 47-70.

2. Madrid RE, Felice CJ (2005) Microbial biomass estimation. Crit Rev Biotechnol 25, 97-112.

3. Pedersen K, Arlinger J, Eriksson S, Hallbeck A, Hallbeck L, Johansson J (2008) Numbers, biomass and cultivable diversity of microbial populations relate to depth and borehole-specific conditions in groundwater from depths of 4-450 $\mathrm{m}$ in Olkiluoto, Finland. ISME J 2, 760-75.

4. White DC (1988) Validation of quantitative analysis for microbial biomass, community structure, and metabolic activity. Arch Hydrobiol Beih Ergebn Limnol 31, 1-18.

5. Jenkinson DS, Ladd JN (1981) Microbial biomass in soil, measurement and turnover. In: Paul EA, Ladd JN (eds) Soil Biochemistry, Marcel Dekker, New York, pp 415-72.

6. Stoeck T, Duineveld GCA, Kok A, Albers BP (2000) Nucleic acids and ATP to assess microbial biomass and activity in a marine biosedimentary system. Mar Biol 137, 1111-23.

7. Berdalet E, Estrada M (1993) Relationships between nucleic-acid concentrations and primary production in the Catalan Sea (Northwestern Mediterranean). Mar Biol 117, 163-70.

8. Blomberg P, Randolph C, Yao CH, Yao MC (1997) Regulatory sequences for the amplification and replication of the ribosomal DNA minichromosome in Tetrahymena thermophila. Mol Cell Biol 17, 7237-47. 
9. Hebert PDN, Ratnasingham S, deWaard JR (2003) Barcoding animal life: cytochrome $c$ oxidase subunit 1 divergences among closely related species. Proc Biol Sci 270, S96-9.

10. Landeweert R, Veenman C, Kuyper TW, Fritze H, Wernars K, Smit E (2003) Quantification of ectomycorrhizal mycelium in soil by real-time PCR compared to conventional quantification techniques. FEMS Microbiol Ecol 45, 283-92.

11. Sylvester JT, Karnati SKR, Yu ZT, Morrison M, Firkins JL (2004) Development of an assay to quantify rumen ciliate protozoal biomass in cows using real-time PCR. J Nutr 134, 3378-84.

12. Tomioka N, Nagai T, Kawasaki T, Imai A, Matsushige K, Kohata K (2008) Quantification of Microcystis in a eutrophic lake by simple DNA extraction and SYBR Green real-time PCR. Microb Environ 23, 306-12.

13. Zhu F, Massana R, Not F, Marie D, Vaulot D (2005) Mapping of picoeucaryotes in marine ecosystems with quantitative PCR of the 18S rRNA gene. FEMS Microbiol Ecol 52, 79-92.

14. Godhe A, Asplund ME, Härnström K, Saravanan V, Tyagi A, Karunasagar I (2008) Quantification of diatom and dinoflagellate biomasses in coastal marine seawater samples by real-time PCR. Appl Environ Microbiol 74, 7174-82.

15. Smith CJ, Nedwell DB, Dong LF, Osborn AM (2006) Evaluation of quantitative polymerase chain reactionbased approaches for determining gene copy and gene transcript numbers in environmental samples. Environ Microbiol 8, 804-15.

16. Adams PS (2006) Data analysis and reporting. In: Dorak MT (ed) Real-Time PCR, Taylor \& Francis, New York, pp 39-62.

17. Fu CJ, Miao W (2006) Cloning and characterization of a new multi-stress inducible metallothionein gene in Tetrahymena pyriformis. Protist 157, 193-203.

18. Rogerson A (1981) The ecological energetics of Amoeba proteus (Protozoa). Hydrobiologia 85, 117-28.

19. Hellunglarsen P, Andersen AP (1989) Cell volume and dry weight of cultured Tetrahymena. J Cell Sci 92, 319-24.

20. Paul JH, Carlson DJ (1984) Genetic material in the marine environment: implication for bacterial DNA. Limnol Oceanogr 29, 1091-7.

21. Danovaro R, Fabiano M, Della Croce N (1993) Labile organic matter and microbial biomasses in deep-sea sediments (Eastern Mediterranean Sea). Deep Sea Res Oceanogr Res Paper 40, 953-65.

22. Kabir S, Rajendran N, Amemiya T, Itoh K (2003) Realtime quantitative PCR assay on bacterial DNA: in a model soil system and environmental samples. J Gen Appl Microbiol 49, 101-9.

23. Hermansson A, Lindgren PE (2001) Quantification of ammonia-oxidizing bacteria in arable soil by real-time PCR. Appl Environ Microbiol 67, 972-6.
24. Poulin R, Luque JL, Guilhaumon F, Mouillot D (2008) Species abundance distributions and numerical dominance in gastrointestinal helminth communities of fish hosts. J Helminthol 82, 193-202.

25. Kapler GM (1993) Developmentally regulated processing and replication of the Tetrahymena rDNA minichromosome. Curr Opin Genet Dev 3, 730-5.

26. Venter JC, Remington K, Heidelberg JF, Halpern AL, Rusch D, Eisen JA, Wu D, Paulsen I, et al (2004) Environmental genome shotgun sequencing of the Sargasso Sea. Science 304, 66-74.

27. Dinsdale EA, Edwards RA, Hall D, Angly F, Breitbart M, Brulc JM, Furlan M, Desnues C, et al (2008) Functional metagenomic profiling of nine biomes. Nature 452, 629-32.

28. Zehr JP, Voytek MA (1999) Molecular ecology of aquatic communities: reflections and future directions. Hydrobiologia 401, 1-8.

29. Moreira D, López-García P (2002) The molecular ecology of microbial eukaryotes unveils a hidden world. Trends Microbiol 10, 31-8.

30. Not F, del Campo J, Balagué V, de Vargas C, Massana $\mathrm{R}$ (2009) New insights into the diversity of marine picoeukaryotes. PLOS ONE 4, e7143.

31. Smith CJ, Osborn AM (2009) Advantages and limitations of quantitative PCR (Q-PCR)-based approaches in microbial ecology. FEMS Microbiol Ecol 67, 6-20.

32. Brodie EL, DeSantis TZ, Moberg Parker JP, Zubietta IX, Piceno YM, Andersen GL (2007) Urban aerosols harbor diverse and dynamic bacterial populations. Proc Natl Acad Sci USA 104, 299-304.

33. Valentini A, Pompanon F, Taberlet P (2009) DNA barcoding for ecologists. Trends Ecol Evol 24, 110-7. 